\title{
Produksi Hijauan, Komposisi Botani dan Kapasitas Tampung di Padang Penggembalaan Alam pada Musim Hujan
}

\author{
Green Production, Botanical Composition, Carrying capacity in Forage Natural \\ Grassland the Effect of Rain Season \\ Sema*, Nurjaya, dan Nurcaya \\ Program Studi Nutrisi dan Teknologi Pakan Ternak \\ Fakultas Pertanian, Universitas Puangrimaggalatung \\ Jl. Sultan Hasanuddin No.27 Sengkang-90915, Sulawesi Selatan, Indonesia \\ *Korespondensi E-mail: sema28292@gmail.com \\ Diterima 16 Nopember 2021; Disetujui 26 Desember 2021
}

\begin{abstract}
ABSTRAK
Kekurangan hijauan pakan menjadi kendala utama para peternak ruminansia sebab penyediaan padang penggembalaan semakin berkurang, Salah satu faktor yang mempengaruhi adalah musim. Penelitian ini telah dilaksanakan di padang penggembalaan alam di Desa Lamata Kecamatan Gilireng, Kabupaten Wajo. Tujuan penelitian untuk mengetahui produksi hijauan, komposisi botanis, kapasitas tampung, di padang penggembalaan alam. Metode yang digunakan dalam penelitian adalah metode analisis deskriptif yaitu menggambarkan kondisi padang penggembalaan. Pengukuran komposisi botanis menggunakan metode "Actual Weight Estimate" dengan menggunakan kuadran ukur $1 \mathrm{~m} \times 1 \mathrm{~m}$. Data yang diperoleh ditabulasi dan dihitung untuk mendapatkan total komposisi botanis, kapasitas tampung. Hasil penelitian menunjukkan bahwa padang penggembalaan Desa Lamata, Kecamatan Gilireng, Kabupaten Wajo memiliki produksi bahan kering sebesar 11,2 ton/ha. Rataan perbandingan nilai penting atau Summed Dominance Ratio (SDR) yaitu rumput 84,42\%, legume 15,58\% dan Rata-rata kapasitas tampung diperoleh 1,5 ST/ha. Kesimpulan yang dapat dirumuskan bahwa areal padang rumput alam di Desa Lamata Kecamatan Gilireng didominasi oleh rumput alam sebesar 84,42 \%, legum 15,58 dan mampu menampung ternak sebanyak 1,5 ST/ha.
\end{abstract}

Kata kunci: Produksi Hijauan, Komposisi Botanis, Kapasitas Tampung, Padang Penggembalaan Alam

\begin{abstract}
Deficiency of forage is the main obstacle for ruminant breeders because the supply of grazing land is decreasing. One of the influencing factors is the season. This research has been carried out in a natural grazing field in Lamata Village, Gilireng District, Wajo Regency. The purpose of the study was to determine forage production, botanical composition, storage capacity, in natural grazing fields. The method used in this research is descriptive analysis method, which describes the condition of the pasture. Measurement of botanical composition using the "Dry Weght Rank" method using a measuring quadrant of $1 \mathrm{~m} \times 1 \mathrm{~m}$.
\end{abstract}


The data obtained were tabulated and calculated to obtain the total botanical composition, carrying capacity. The results showed that the pasture of Lamata Village, Gilireng District, Wajo Regency had dry matter production of 11.2 tons/ha. The value of Summed Dominance Ratio (SDR) of grass was $84.42 \%$, legumes $15.58 \%$ and the average carryng capacity $1.5 \mathrm{ST} / \mathrm{ha}$. The conclusion that can be formulated is that the natural grassland area in Lamata Village, Gilireng District is dominated by natural grass by $84.42 \%$, leguminose $15,58 \%$ and is able to accommodate $1.5 \mathrm{ST} /$ ha livestock.

Keywords: Forage Production, Botanical Composition, Carrying capacity, Natural Grassland.

\section{PENDAHULUAN}

Kabupaten Wajo adalah salah satu daerah sentra pengembangan ternak ruminansia terutama sapi potong dengan luas padang pengembalaan secara keseluruhan seluas 190,000 hektar, dengan jumlah populasi sapi potong sebesar 1.431 ekor (BPS, 2021). Populasi ternak ini pada umumnya memanfaatkan sumber hijauan pakan dari padang rumput. oleh karena itu patut menjadi perhatian untuk meningkatkan produktivitas padang pengembalaan setiap tahunnya melalui innovasi teknologi. Inovasi teknologi yang diterapkan berupa pemanfaatan pakan lokal yang bersumber dari hijauan sebagai bahan pakan bergizi atau pakan komplit yang bernilai gizi tinggi (Hasan, dkk., 2020).

Hijauan merupakan faktor penentu keberhasilan dalam pengembangan peternakan. Untuk memenuhi kebutuhan ternak maka dibutuhkan hijauan yang mempunyai kualitas tinggi, kuantitas yang cukup serta ketersediaan dapat berkelanjutan. Penyediaan pada padang pengembalaan dapat berupa rumput dan legume dengan komposisi rumput $60 \%$ dan legume $40 \%$. Hijauan memegang peranan penting bagi ternak ruminansia khususnya ternak sapi, besarnya sumbangan hijauan bagi ternak ruminasia $74-94 \%$ atau bisa mencapai $100 \%$.

Padang pengembalaan merupakan basis ekologi sumber hijauan pakan untuk pengembangan ternak ruminansia di daerah tropis. Dengan perubahan musim, dari musim hujan ke musim kemarau memberikan gambaran bahwa produksi dan kualitasnya akan bergeser terutama pada musim kemarau. Mutu padang pengembalaan dapat dilakukan melalui penilaian komposisi botanis, produksi dan kualitas hijauan masih belum diketahui dengan tepat. Dalam usaha menuju kearah itu maka penelitian untuk menentukan produksi hijauan, komposisi botanis dan kapasistas tampung padang pengembalaan perlu dilakukan.

Rinduwati dkk., (2016) melaporkan bahwa salah satu cara untuk melakukan penilaian mutu padang pengembalaan dalam skala luas adalah melalui teknik penginderaan jauh (pendekatan spasial). Teknologi penginderaan jauh ini akan menghasilkan data yang merupakan data hasil pantulan objek ari berbagai gelombang yang ditangkap oleh sebuah sensor dan mengubahnya menjadi data numerik serta bisa dilihat dalam bentuk grafik atau citra dengan menggunakan Geografis Information system (GIS)

GIS dapat menjadi alat bantu analisis penenntuan paka lokal pada padang pengembalaan. Pendekatan spasial system informasi geografis memanfaatkan data dasar 
geografis dipadukan dengan data temuan lapangan. Pemetaan sumberdaya lahan dengan menggunakan citra satelit dengan teknik GIS dapat mereduksi biaya minimal 25\% dibandingkan dengan pemetaan sumberdaya lahan konvensional untuk luasan 0,5 juta hektar.

Penelitian bertujuan untuk mengetahui potensi hijauan pakan lokal dengan menggunakan pendekatan spasial dalam pengukuran produksi biomassa, komposisi botanis serta kapasitas tampung setiap perubahan musim.

\section{MATERI DAN METODE}

\section{Materi}

Materi penelitian adalah semua jenis rumput dan legum yang tumbuh di atas areal padang penggembalaan alam di lokasi penelitian yaitu Desa Lamata kecamatan Gilireng Kabupaten Wajo dan alat-alat yang digunakan berupa kuadran $1 \mathrm{~m} \times 1 \mathrm{~m}$, sabit, gunting, kantong plastik, timbangan, kalkulator, camera, dan GPS (Global Position System).

\section{Metode}

Metode yang digunakan dalam penelitian ini adalah metode Deksriptif dengan melakukan survei langsung di lapangan, diikuti pengukuran dan pengamatan dengan menggunakan teknologi perangkat lunak GIS meliputi pengolahan data.

Data yang diambil dalam penelitian ini adalah data primer dan data sekunder. Data primer diperoleh dari hasil pengukuran langsung di lapangan, sedangkan data sekunder bersumber dari literatur dan instansi terkait. Jenis data primer yang diambil adalah produksi hijauan, komposisi botani, dan kapasitas tampung berdasarkan data produksi yang ada.

\section{Prosedur Pengambilan Data untuk Produksi Hijauan Makanan Ternak}

Metode yang digunakan dalam pengambilan data produksi hijauan makanan ternak adalah metode survei serta pengukuran dan pengamatan langsung di lapangan. Pengukuran produksi hijauan dilakukan dengan menggunakan metode "Actual Weight Estimate", Halls et al., (1964) dalam Susetyo (1980) yaitu dengan menggunakan frame berukuran $1 \mathrm{~m} \times 1 \mathrm{~m}$. Penempatan frame dalam padang rumput dilakukan secara acak sistematis, setelah itu dilakukan pemotongan vegetasi atau metode destruksi (kemudian dimasukkan ke dalam kantong plastik untuk segera ditimbang).

\section{Prosedur Pengambilan Data untuk Komposisi Botani}

Metode yang digunakan dalam pengambilan data komposisi botani yaitu metode pengukuran secara langsung yangdibagi beberapa metode, diantaranya dengan metode pengukuran perbandingan nilai penting atau Summed Dominance Ratio (SDR) berdasarkan frekuensi (keseringan), density (kepadatan).

Prosedur kerjanya sebagai berikut :

a. Menggunakan kuadran untuk pengambilan sampling plot. Bingkai kuadran yang digunakan berukuran $1 \mathrm{~m} \times 1 \mathrm{~m}$.

b. Melakukan pelemparan bingkaikuadran secara acak pada daerah pengamatan dengan tujuan untuk penentuan titik awal atau titik pusat. 
c. Pada daerah pengamatan dilakukan penempatan plot pertama untuk titik awal dilakukan pelemparan, darititik awal tersebut penempatan plot pertama keempat arah mata angin timur, barat, utara, selatan dengan metode yang sama dan masing-masing arah sebanyak 20 plot.

d. Melakukan observasi jenis vegetasi, dan penyebaran jenis yang ada pada setiap plot dan menentukan besar frekuensi, kerapatan dan dominansi setiap jenis dengan cara menghitungsetiap vegetasi yang ada dalam seti plot pengamatan.

\section{Variabel Penelitian}

Variabel yang diukur dalam penelitian ini adalah Produksi bahan segar, produksi bahan kering, komposisi botanis dan kapasitas tampung berdasarkan metode Tjitrosoedirdjo dkk., (1984); Novalinda dkk., (2014).

\section{Analisis Data}

Semua data primer yang diperoleh ditabulasi dan dihitung untuk mendapatkan persentase komposisi botani dan rata-rata produksi bahan segar dan bahan kering hijauan serta kapasitas tampung, selanjutnyadianalisis menggunakan metode deskriptif.

\section{HASIL DAN PEMBAHASAN}

\section{Produksi Bahan Segar dan Bahan kering}

Produksi bahan segar dan bahan kering hijauan pakan merupakan fungsi dari faktor internal spesies tanaman dan faktor eksternal berupa tanah dan iklim dan merupakan sumber pakan utama ternakruminansia. 70\% dari makanan ternak ruminansia berasal dari hijauan (Nitis dkk., 1992), sehingga ketersediaan pakan baik dari segi kuantitas, kualitas dan secara berkesinambungan sepanjang tahun perlu diperhatikan. Dari hasil penelitian dapat diketahui bahwa pada padang penggembalaan di Desa Lamata, Kecamatan Gilireng Kabupaten Wajo memiliki produksi bahan segar dan bahan kering hijauan pakan awal musim hujan dapat dilihat pada Tabel 1.

Tabel 1. Rerata Produksi Bahan Segar dan Bahan Kering Hijauan Pakan Padang Penggembalaan (ton/ha)

\begin{tabular}{ccc}
\hline Komposisi Botani & $\begin{array}{c}\text { Produksi Hijauan Segar } \\
\text { (ton/ha) }\end{array}$ & $\begin{array}{c}\text { Produksi Bahan Kering } \\
\text { (ton/ha) }\end{array}$ \\
\hline Rumput & 56,00 & 11,20 \\
Legum & 9,00 & 1,80 \\
\hline Total & 65,00 & 13,00 \\
\hline
\end{tabular}

Sumber : Data Primer Hasil Olahan, 2021

Tabel 1 menggambarkan bahwa produksi bahan segar hijauan pakan pada awal musim hujan di kawasan penelitian 56 ton/ha sedangkan produksi bahan kering 11,20 ton/ha. Angka ini cukup tinggi dibandingkan dengan produksi hijauan pakan pada musim hujan Kecamatan Kupang sebesar 1.029,44 kg atau 1,03 ton/Ha bahan segar sedangkan 
bahan kering sebesar 960,52 $\mathrm{kg}$ atau 0,96 ton/Ha (Wolutana, 2015). Banyak faktor yang mempengaruhi pertumbuhan dan produksitanaman pakan selain faktor tanaman itu sendiri. Faktor eksternal yang berhubungan langsung dengan pertumbuhan dan produksi adalah curah hujan dan suhu. Curah hujan yang cukup akan menjamin ketersediaan air yang dapat dimanfaatkan oleh tanamandalam proses fisiologis. Faktor suhu juga berpengaruh langsung dan berkaitan erat dengan laju transpirasi. Pada suhu melampaui kebutuhan dalam proses fotosintesis, maka kecepatan fotosintesis neto akan berkurang yang akan mempengaruhi produksi dan kualitastanaman pakan. Umumnya akan terjadi penurunan nilai cerna karena kecepatanproses lignifikasi pada dinding sel ketika temperatur meningkat.

Pergantian musim hujan dan musim kemarau memberikan pengaruh yang negatif terhadap kualitas dan kuantitas hijauan pakan yang tersedia di padang penggembalaan alam (Manu, 2013). Produksi hijauan padang penggembalaan alam dapat mencapai tiga kali lipat pada musim hujan dibandingkan dengan musim kemarau tetapi memiliki mutu yang rendah (Muhajirin dkk., 2017).

\section{Komposisi Botani}

Komposisi botani adalah angka yangdigunakan untuk menentukan peniliaian secara kualitatif terhadap padangpenggembalaan alam yang dapat mempengaruhi aktivitas ternak (Farizaldi, 2011). Metode peningkatan dan manajemen praktis dalam rangka menjaga kesehatan ekositem padang penggembalaan antara lain melalui pemupukan dan pemotongan secara berkala. Pemupukan seperti penggunaan pupuk komerisial dapat meningkatkan produksi padang penggembalaa. Hasil penelitian memperlihatkan bahwa komposisi botani dalam areal padang penggembalaan disajikan pada Tabel 2.

Tabel 2. Nilai Summed Dominance Ratio (SDR) Pada Padang Penggembalaan Aalam pada Musim Hujan

\begin{tabular}{clccccc}
\hline No. & Jenis/Spesies & $\sum \mathrm{Km}$ & $\begin{array}{c}\text { Kn } \\
(\%)\end{array}$ & $\sum \mathrm{Fm}$ & $\begin{array}{c}\text { Fn } \\
(\%)\end{array}$ & $\begin{array}{c}\text { SDR } \\
(\%)\end{array}$ \\
\hline 1 & Rumput & 8,15 & 99,25 & 64,72 & 74,57 & 84,42 \\
2 & Leguminosa & 7,00 & 0,75 & 35,28 & 25,43 & 15,58 \\
\hline Total & 15,15 & 100 & 100 & 100 & 100 \\
\hline
\end{tabular}

Sumber: Data Primer Hasil Olahan, 2021

Tabel 2 nampak bahwa nilai perbandingan nilai penting atau Summed Dominance Ratio (SDR) rumput yang ada di padang penggembalaan alam sangat dominan dengan rataan $84,42 \%$, sedangkan leguminosa sebesar 15,58\%. Hal ini menunjukkan bahwa padang penggembalaan di Desa Lamata Kecamatan Gilireng didominasi oleh rumput. Kurangnya tanaman leguminosa di padang rumput alam menyebabkan rendahnya kualitas hijauan, karena selain kandungan nutrisi yang lebih tinggi dalam leguminosa dibandingkan rumput, namun tanaman leguminosa juga memberikan kontribusi terhadap penyediaan nitrogen melalui fiksasi N. Hal ini penting dalam mengelola padang penggembalaan sehingga menjaga kualitas padang secara berkelanjutan. Whiteman (1980), padang penggembalaan yang ideal adalah proporsi rumput dan legum adalah 
60:40\%. Sanchez (1993) menyatakan bahwa salah satu penyebab rendahnya presentase leguminosa adalah karena agak alkalisnya tanah, sehingga menyebabkan tanaman sulit menyerap ion-ion unsur hara tanah.

Komposisi botani dalam padang penggembalaan dipengaruhi oleh beberapa faktor. Harris dan Brogham (1967) menyatakan bahwa komposisi botani dipengaruhi oleh penaburan benih, tipe dan karakteristik tanah, penggunaan pemupukan dan ukuran paddock. Secara umum, komposisi botani akan menentukan kualitas padang penggembalaan, namun kandungan nutrisi tanaman pakan dalam areal padang penggembalaan dipengaruhi oleh faktor-faktor antara lain tingkat kedewasaan tanaman, faktor tanah, species tanaman, iklim, kelas ternak dan kondisi padang (Oelberg, 1956). Faktor iklim seperti temperatur, kelembaban, curah hujan, intensitas cahaya dan ketinggian tempat merupakan faktor utama dalam mempengaruhi nilai nutrisi dan produksi tanaman pakan. Curah hujan secara langsung maupun tidak langsung akan mempengaruhi kualitas tanaman pakan. Curah hujan secara umum meningkatkan kandungan nitrogen, pospor dan lemak kasar tanaman pakan. Sebaran tanaman pakan dalam padang penggembalaan dipengaruhi oleh kemiringan lereng, ketinggian tempat, penutupan permukaan, total bahan organik, total nitrogen dan intensitas penggembalaan ternak. Dari semua faktor tersebut, faktor ketinggian tempat yang berpengaruh banyak terhadap penyebaran kelompok tanaman,sedangkan penggembalaan ternak merupakan faktor utama terjadi degradasi padang (Kagar dkk., 2017).

Leguminosa dapat dijadikan sebagai indikator dalam menentukan keadaan kualitas hijauan pada suatu padang penggembalaan. Persentase leguminosa pada Tabel 2 menunjukkan bahwa kualitas padang penggembalaan di Desa Lamata, Kecamatan Gilireng Kabupaten Wajo masih rendah. Hal ini sesuai dengan pendapat Whiteman (1980) bahwa leguminosa juga mempunyai peranan yang sangat penting dalam penggunaan padang rumput sebagai sumber utama hijauan makanan ternak, karena mampu meningkatkan nilai gizi hijauan padang penggembalaan, menaikkan produksi per satuan luas tanah dan dapat meningkatkan derajat kesuburan tanah lewat fiksasi nitrogen bebas dariudara oleh bakteri rhizobium yang ada pada nodule akar legum tersebut. Gulma merupakan salah satu tumbuhan yang kurang di sukai oleh ternak dan hanya berfungsi sebagai pengganggu atau predator dari pertumbuhan rumput dan leguminosa yang ada pada padangpenggembalaan, namun dilokasi penelitian tidak ditemukan gulma.

\section{Kapasitas Tampung}

Kapasitas tampung (Carrying Capacity) adalah kemampuan padang penggembalaan untuk menghasilkan hijauan makanan ternak yang dibutuhkan oleh sejumlah ternak yang digembalakan dalam satuan luasan tertentu kemampuan padang penggembalaan untuk menampung ternak per hektar. Kapasitas tampung merupakan kemampuan dalam menganalisis suatu areal lahan pasture dalam menampung sejumlah ternak, sehingga kebutuhan hijauan terpenuhi dengan cukup dalam satu tahun, Rinaldi dkk., ( 2012); Rusnan dkk., (2015).

Daya tampung (carrying capacity) penggembalaan mencerminkan keseimbangan antara hijauan yang tersedia dengan jumlah satuan ternak yang digembalakan di dalam 
per satuan waktu (Rusdin dkk., 2009). Kapasitas tampung berhubungan erat dengan produktivitas hijauan pakan pada suatu areal penggembalaan ternak. Makin tinggi produktivitas hijauan pada suatu areal padang penggembalaan, makin tinggi pula kapasitas tampung ternak yang ditunjukkan dengan banyaknya ternak yang dapat digembalakan (Reksohadiprodjo, 1994)

Kapasitas tampung atau kapasitas penggembalaan menggambarkan tentang jumlah maksimum ternak dalam padang yang dapat ditopang tanpa mengurangi sumberdaya yang tersedia seperti tanaman dan tanah. Kapasitas penggembalaan sangat dipengaruhi olehbeberapa faktor seperti kemiringan lereng, jarak ke sumber air dan naungan. Kapasitas penggembalaan akan semakin menurun seiring dengan semakin jauhnya sumber air, semakin tinggi kemiringan lereng dan semakin banyak canopy tanaman dalam padang penggembalaan (George et al., 2020). Lebih lanjut dinyatakan bahwa jika kemiringan lereng $30-60 \%$, maka kapasitas penggembalaan menuruan hingga $60 \%$ sedangkan jika kemirngan lereng $>60 \%$ kapasitas penggembalaan turun hingga $100 \%$.

Hasil yang diperoleh dalam penelitian ini menunjukkan bahwa kapasitas tampung atau kapasitas penggembalaan di areal padang penggembalaan Alam Desa Lamata, Kecamatan Gilireng, Kabupaten Wajo sebesar 1,5 UT/Ha. Angka yang diperoleh dalam penelitian diestimasi berdasarkan hasil pengukuran berat dari tanaman pakan yang diperoleh selama pengumpulan data yangdiestimasi dengan menggunakan rumus Voison $(\mathrm{Y}-1) \mathrm{s}=\mathrm{r}$ dimana $\mathrm{Y}=$ kebutuhan luas tanah per tahun terhadap kebutuhan per bulan sedangkan $\mathrm{s}=$ periode merumput $(30 \mathrm{Hari})$ dan $\mathrm{r}=$ periode istirahat $(70$ hari). Data yang diperoleh dalam penelitian berbeda dan lebih tinggi dari pada yang dilaporkan Kleden dkk., (2015) yang menyatakan bahwa kapasitas tampung padang penggembalaan sebesar 0,38 ST/Ha/thn. Hasil yang diperoleh dalam penelitian ini lebih rendah dari yang dilaporkan Yoku dkk., (2014) yang melaporkan bahwa kapasitas tampung padang penggembalaan di kawasan Bitawi kampung Inam Papua Barat sebesar 1,77 ST/ha/thn. Adanya perbedaan ini disebabkan oleh perbedaan lokasi penelitian dan waktu pelaksanaan penelitian. Seperti diketahui setiap lokasi memiliki sifat fisik dan kimia tanah yang mempengaruhi pertumbuhan dan produksi tanaman pakan dalam areal padang penggembalaan. Waktu pelaksanaan juga berhubungan erat dengan musim hujan atau kemarau yang mempengaruhi ketersediaan air dalam mendukung proses fisiologi tanaman.

\section{KESIMPULAN}

Produksi bahan kering hijauan pada padang penggembalaan alam awal musim hujan di Desa Lamata Kecamatan Gilireng didominasi oleh rumput alam sebesar 84,42 \%, legum $15,58 \%$ dan mampu menampung ternak sebanyak 1,5 ST/ha.

\section{UCAPAN TERMAH KASIH}

Penulis mengucapkan terima kasih kepada Kementerian Riset dan Teknologi/ Badan Riset dan Inovasi Nasional Deputi Bidang Penguatan Riset dan Pengembangan yang telah memberikan bantuan pendanaan dengan Nomor Kontrak 070/SP2H/LT/DRPM/2021 
melalui skim Penelitian Dosen Pemula (PDP) Tahun 2021. Kepada Rektor Uniprima, LPPM dan Civitas Akademika Fakultas Pertanian Uniprima diucapkan terima kasih atas dukungan sarana dan perasarana selama penelitian berlangsung. Kepada Pengelolah Jurnal Ilmu dan Industri Peternakan (JIIP) UIN Alauddin Makassar kami ucapkan banyak terimah kasih telah menfasilitasi publikasi artikel ini.

\section{DAFTAR PUSTAKA}

Badan Pusat Statistik. 2020. Sumba Timur Dalam Angka. Kabupaten Sumba Timur. Katalog. 1399013.5302.

Badan Pusat Statistik. 2021. Wajo Dalam Angka. Kabupaten Wajo. ISSN: 0215-6822 No. Publikasi/Publication Number: 73130.2104 .

Farizaldi. 2011. Produktivitas hijauan makanan ternak pada lahan perkebunankelapa sawit berbagai kelompok umur di PTPN 6 Kabupaten Batanghari Provinsi jambi. Jurnal Ilmiah Ilmu- Ilmu Peternakan, 14, 68-73.

George, M.R., William, F., and McDougald N. 2020. Ecology and Management of Annual Rangelands. Chapter 8 Grazing Management.

Harris, W., and Brougham, R.W. 1967. Some factors affecting change in botanical composition in a rye grass-white clover pasture under continuous grazing. New Zealand Journal of Agricultural Research, 11(1),15-38.

Hasan, S., Mujnisa, A., Khaerani, P. I., and Natsir, A. 2020. Potential of complete feed formulated from local raw materials on beef cattle performance. EurAsian Journal of BioSciences, 14(1), 1-6.

Kargar, C.H., Javadi, S.A., Amiri, G.Z., dan Khajeddin, S.J. 2017. Vegetation composition differentiation and species-environment relationships in the northern part of Isfahan Province, Iran. Journal of Arid Land, 9(2017),161-175.

Kleden, M.M., Ratu M.R.D., dan Randu, M.D.S. 2015. Kapasitas tampung hijauan pakan dalam areal perkebunan kopi dan padang rumput alam di kabupaten flores timur ntt. JurnalZootek, 35 (2), 340-350.

Manu, A.E. 2013. Produksi padang penggembalaan sabana Timor Barat. Pastura, 3(1), 25-29.

Muhajirin, Despal, dan Khalil. 2017. Pemenuhan kebutuhan nutrien sapi potong bibit yang digembalakan di padang mengatas. Buletin Makananternak, 104(1), 9-20.

Nitis, I.M., Lana, K., Sudana. I.B., dan Sutji N. 1992. Pengaruh klasifikasi wilayah terhadap komposisi botani hijauan yang diberikan pada kambing di Bali di waktu musim kemarau. Pro. SeminarPenelitian Peternakan, Bogor.

Novalinda, R., Zuhri, S., dan Solfiyeni. 2014. Analisis vegetasi gulma pada perkebunan karet (Hevea brasiliensis Mull.Arg.) di Kecamatan Batang Kapas, Kabupaten Pesisir Selatan, J. Bio. UA, 3(2), 129-13.

Oelberg, K. 1956. Factor affecting the nutritive value of range forage. Journal of Range Management, 9(5), 220-225

Reksohadiprodjo, S. 1985. Produksi Tanaman Hijauan Makanan Ternak Tropik. BPFE, Yogyakarta.

Rinaldi, R., Hairul, B., dan Manfarizah. 2012. Bahaya erosi dan upaya konservasi padang penggembalaan sapi di aceh besar. Jurnal Manajemen Sumber DayaLahan, 1(2), 136145. 
Rusdin., Ismail, M., Purwaningsih, S., Andriana, A., dan Dewi, S.U. 2009. Studi potensi kawasan lore tengah untuk pengembangan sapi potong. MediaLitbang Sultel, 2(2), 94-103.

Rinduwati., Hasan, S., Syamsu, J.A., and Useng, D. 2016. Carrying capacity and botanical diversity of pastoral range in Gowa Regency. Int. J. Sci. Basic and Appl. Res, 29(3), 105- 111.

Rusnan, H., Kaunang, C.L, dan Tulung, Y.L.R. 2015. Analisis potensi dan strategi pengembangan sapi potong dengan pola integrasi kelapa-sapi di Kabupaten Halmahera Selatan Provinsi Maluku Utara. Jurnal Zootek, 35(2), 187-200.

Sanchez, P. A. 1993. Sifat dan Pengelolaan Tanah Tropika. Jilid 2 (Terjemahan). Institut Teknologi Bandung, Bandung.

Susetyo, S. 1980. Padang Penggembalaan. Departemen Ilmu Makanan Ternak. Fakultas Peternakan, IPB. Bogor.

Tjitrosoedirdjo, S., Utomo I.H., dan Wiroatmodjo J. 1984. Pengelolaan Gulma di Perkebunan. PT Gramedia, Jakarta.

Whiteman, P.C. 1980. Tropical PastureSience. Oxford University Press, US

Wolutana, A.H., 2015. Komposisi botani dan produksi hijauan makanan ternak musim kemarau pada padang penggembalaan di Kecamatan Kupang Timur Kabupaten Kupang. Skripsi. Fakultas Peternakan. Universitas Nusa Cendana, Kupang.

Yoku, O., Andoyo, S., Trisiwi, W., dan Iriani, S.2014. Produksi padang penggembalaanalam dan potensi pengembangan sapibali dalam mendukung program kecukupan daging di papua barat. Pastura, 3(2),102-10. 